\title{
II. On the hindoo formulæ for computing eclipses, tables of sines, and various astronomical problems
}

\section{Delambre}

To cite this article: M. Delambre (1807) II. On the hindoo formulæ for computing eclipses, tables of sines, and various astronomical problems, Philosophical Magazine Series 1, 28:109, 18-25, DOI: $10.1080 / 14786440708563474$

To link to this article: http://dx.doi.org/10.1080/14786440708563474

Published online: 18 May 2009.

Submit your article to this journal $₫$

Џ Article views: 3

Q View related articles $\square$ 
tion had the properties of pure potash; and when it had been saturated with nitric acid it gave no turbidness by mixture with solution of muriate of barytes: the acid matter exposed to a strong heat evaporated without leaving any residuum.

[To be continued.]

11.. On the Hindoo Formula for computing Eclipses, Tables of Sines, and various Astrononical Problems. By $M$. Dleambre*.

$\mathrm{T}$ HESE formule may be found in the second volume of the Asiatic Rescarchcs, or Memroirs of the Society established at Calcutta; the two first volumes of which have lately beer translated into French, and published in 1805 from the Imperial printing-office.

Although these formulæ must have been known in Europe for some time, yet as the original memoirs, printed first at Calcutta, and since reprinted in London, are very rare in France, we thought it our duty to announce them to our readcrs, many of whom, most likely, have not beard of them.

Ducham, Bailly, and Le Gentil, have mentioned that the Indians possess methods of computing eclipses, which they follow without understanding. Mr. Daris, the English anthor of this memoir, has atlacked this assertion vietoriously, by giving at full length the computation of the eclipse of the moon of November 1789 , by means of the Indian formula, of which be bas given the demonstration and explanation according to the Souria Siddanta. Want of room obliges us to suppress these details; observing merely, that we have revised the computations with attention, and that, excepting a few points of the Indian dectrine, and a few suppositions whose foundations are not very intelligible, we can declare that all the rest are as clear as the composition of the subject will

* From the Connoissance des Temps for 1808 . Translated by 'T.S. Evans, F.L.S.-The ingenious method contained in this paper for computing Sinc's, and explained by M. Dẹlambre, is curioss, and will prove interesting to our astrononical readers. 
admit : but I cannot.forbear saying a few words on the Indian tables of sines, and of the two methods by which they have been computed; for, since they have been printed, I have found that in the note put at the bottom of this table I have not safficiently appreciated the excellence of the method, from having been drawn into an error by a constant number, which does not appear to have been given accurately enough in the memoir.

In this table the sines are expressed in minutes; they proceed by intervals of $3 \frac{3}{4}$ degrees, and suppose the radius 3438 , or rather $3437 \cdot 75$. On the side of the right sines it gives the versed sines.

If we examine the process recommended by the Indian author, we readily perceive that his method is reduced to the computing beforehand a first difference, which is at the same time the first sine of the table; after whici, to obtain the second sine, he calculates the second difference, which he subtracts from the first difference; this gives him the first difference between the first and second sinc, and then the second sine: after this he computes another second difference, to obtain a new first difference aud a new sine, and so on to the end of the tab!e. This process is exactly that which $I$ have pointed out in the preface to Borla's Decimal Tables, without knowing that the method which appeared unknown even to the moderns, had been praçtised so long ago in India.

$\mathrm{My}{ }^{*}$ formula is $\Delta^{\prime} 2^{\prime} s, \mathrm{~A}=-4 s^{2}, \frac{1}{2} \Delta \mathrm{A} s, \mathrm{~A}=(- \text { chord })^{2}$ $\Delta A s, A$. (See page 48 of the Decimal Tables.)

$\Delta A$ being a constant quantily in a table of sines, it follows, that to obtain the second difference of any sine whatever, it is necessary to multiply this sine by a constant number: now $\Delta A$ in the Indian tables is $3^{\circ} 45^{\prime}$, therefore $4 s^{2}$, $\frac{1}{2} \Delta \mathrm{A}=4 s^{2}, 1^{\circ} 52^{\prime} 30^{\prime \prime}=0.0042821=\frac{\mathrm{t}}{233.53}$; whence it follows, that the constant factor to find the second difference is $\frac{1}{233^{\circ} 53}$; that is to say, the last found sine must be

* Delambre uscs $\Delta$ to denote first difference, and $\Delta^{(3)}$ to denote second difference. 
divided by $\frac{1}{233.53}$ : but according to the memoir this cort* stant divisor is $\frac{1}{225}$, which makes me think there is an error of the press; and the more so, as the Indian author's numbers do not agree well with this divisor 225, but, instead of which, with my divisor $\frac{1}{233^{\circ} 53}$; and following the precept literally, I find the Indian numbers very nearly as we may perceive.

\begin{tabular}{|c|c|c|c|c|c|}
\hline & & Indian Sines. & $\begin{array}{c}\text { Sines by my } \\
\text { Divisor. }\end{array}$ & $\begin{array}{c}\text { First } \\
\text { Differences. }\end{array}$ & $\begin{array}{c}\text { Second } \\
\text { Differences. }\end{array}$ \\
\hline $0^{\circ}$ & & 000 & $000^{\circ} 00$ & 94 & \\
\hline 3 & 45 & 225 & $224 \cdot 85$ & & 0.96 \\
\hline 7 & 30 & 440 & $448 \cdot 75$ & & $1 \cdot 92$ \\
\hline 11 & 15 & 671 & 670.71 & $\begin{array}{l}221 \cdot 97 \\
\text { 910.0 }\end{array}$ & $2 \cdot 87$ \\
\hline 15 & 0 & 890 & $889 \cdot 81$ & & $3 \cdot 81$ \\
\hline 18 & 45 & 1105 & $1105 \cdot 10$ & & $4 \cdot 73$ \\
\hline 22 & 30 & $1315^{*}$ & $1315 \cdot 56$ & & $5 \cdot 63$ \\
\hline 26 & 15 & $1520^{*}$ & $1520 \cdot 59$ & 204 & $6 \cdot 51$ \\
\hline 30 & 0 & 1719 & $1710^{\circ} 01$ & \pm 2 & $\pi \cdot 36$ \\
\hline 33 & 45 & 1910 & 1910.07 & & $8 \cdot 18$ \\
\hline 37 & 30 & 2093 & $2092 \cdot 95$ & & $8 \cdot 96$ \\
\hline 4.1 & 15 & 2267 & $2266 \cdot 85$ & & $9 \cdot 71$ \\
\hline 45 & 0 & 2431 & $2431 \cdot 08$ & & 10.41 \\
\hline 48 & 45 & 2585 & $2584 \cdot 88$ & & $11 \cdot 07$ \\
\hline 52 & 30 & 2728 & $2727 \cdot 61$ & & $11 \cdot 68$ \\
\hline 56 & 15 & 2859 & 2858.66 & & $12 \cdot 24$ \\
\hline 60 & 0 & $2978^{*}$ & $2977 \cdot 47$ & & $12 \cdot 75$ \\
\hline 63 & 45 & $308 t$ & 3083.55 & & $13 \cdot 20$ \\
\hline 67 & 30 & $3177^{*}$ & $3176 \cdot 30$ & & $13 \cdot 61$ \\
\hline 71 & 15 & 3256 & $3255 \cdot 54$ & $65 \cdot 31$ & $13 \cdot 94$ \\
\hline $75 \cdots$ & $: 0$ & 3321 & $3320 \cdot 95$ & & $14 \cdot 22$ \\
\hline 78 & 45 & 3372 & 3372.04 & 36.65 & $14 \cdot 44$ \\
\hline 82 & $30^{\mathrm{m}}$ & 3409 & $\mathbf{3 4 0 8} \cdot 59$ & $22 \cdot 05$ & $14 \cdot 60$ \\
\hline 86 & 15 & 3431 & $3430 \cdot 74$ & $\begin{array}{r}2203 \\
+7.36\end{array}$ & 14.69 \\
\hline 90 & 0 & 3438 & $3438 \cdot 10$ & $-7 \cdot 36$ & $14 \cdot 72$ \\
\hline 93 & 45 & & $3430 \cdot 74$ & & \\
\hline
\end{tabular}

This table supposes the radius greater than $3437 \cdot \tau$, and less than 3438.4; according to Archimcles the radius would be between 3436.3 and 3438.5 ; mean 3437.4 . 
It is evident that, exceptingr a few sines, in which we differ some tenths, the agreement is perfect throughout the table; but with the divisor 225 we obtain only the three first sines with any accuracy, after which the error increases very rapidly. I suppose this false divisor is only a repetition of the divisor 225 , which served to find the first of the first differences.

The Indian author does not show, how he found his divisor; we can therefore only examine it by the work : now the work shows that a divisor differing very little from mine must be used.

This process is extremely curious; nothing like it is to be found in Ptolemy's Trigonometry, and all the authors on that subject were turned over to no purpose before we could find any vestige of it, till we came to Briggs, who was acquainted with this divisor, which he appeared to have discovered by the work, after comparing the second differences found out by other methods. Briggs himself did not know that it was the square of the chord of the differential $\operatorname{arc} \Delta \mathrm{A}$.

But it may be asked why the Indians have made $\Delta \mathrm{A}=$ $3^{\circ} 45^{\prime}$ instead of $1^{\circ}$. The following, I think, is the reason; it appears to carry great probability:-It cannot be doubted that the Indians were acquainted with the following theorems: $s^{2}, \mathrm{~A}+c^{2}, \mathrm{~A}=\operatorname{rad}_{.}{ }^{2}$; ver. $\sin , \mathbf{A}=\operatorname{rad} .-\cos , \mathbf{A}$ $=2 s^{2}, \frac{1}{2} \mathrm{~A}$; whence $s, \frac{1}{2} \mathrm{~A}=\left(\frac{1}{2} \mathrm{rad} \text {. }-\frac{1}{2} c, \mathrm{~A}\right)^{\frac{1}{2}}$. Now these three theorems are sufficient to find all the sines of their table, and will not give any other: they have therefore done all that therwere able to do, and their tableshows us the bounds of their knowledge: we see, indeed, p. 290 , that they have actually used these three formule to compute their table, and that they knew, besides, that $s, 30^{\circ}=\frac{1}{2}$ rad., which appears to leave not a coubt respecting what $I$ have'said. Their table being constructed, they then examined the first and second differences, and remarked that the first constantly decreased, but they could not immediately perceive according to what law; the second differens 's, on the contrary, continually increased, and it was not ifficult to perceive that they were 
proportional to the sine : thus the second difference opposite $30^{\circ}$ is $7 \cdot 36$, and that opposite $90^{\circ}$ is $14 \cdot 72$, double of the former: and to find the ratio of the second difference to the sine they divided the radius $3437 \cdot 75$ by $14 \cdot 72$, and they found 233.53 for their quotient : dividing thus each sine by its second difference they constantly found this same quotient, whence they concluded that to obtain this second difference it was only necessary to divide the sine by 233.53 .

The rule for the first differences is not so simple; for the difference of $s, \mathrm{~A}=2 s, \frac{1}{2} \mathrm{~A} c,\left(\mathrm{~A}+\frac{1}{2} \Delta \mathrm{A}\right)$, and the $s,(\mathrm{~A}+$ $\left.\frac{3}{x-1} \Delta \mathrm{A}\right)$, are not in the table.

But the first of the first differences is at the same time the first sine of the table; whence they concluded, that with the first sine, and the first of the first and second differences, they were fully prepared for computing all the rest: but in the rvork the table was already computed throughout, when it gave them their differential method; and the proof of this is, that to make their table as they have given it they had occasion to make the first sine 224.85 and not 225 , which would have given the first differences a little too great, and the sines too small.

It is true the Sonria Siddanta recommends to divide the number of minutes in a sign by 8 to obtain the first sine, which is the same as making the sine equal to the arc; thus $\frac{30^{\circ}}{8}=\frac{360^{\circ}}{56}=\frac{2 \cdot 600^{\prime}}{96}=225^{\prime}=3^{\prime} 45^{\prime}$; instead of which the true value found by the above theorems is only $224 \cdot 85$.

Let it be observed that there is nothing conjectural but the reasoning which I have given them, for they really possessed all the knowledge which I suppose them to have had. I do not pretend, however, that they used decimal fractions; it is only to shorten the work that $I$ have used them in reconstructing their table of sines, for it is well known all their calculations were made in sexagresimals.

By taking proportional parts, the use of which was well known to them, they might have extended their table to every degree; but these interpolated degrees would have had their signs less accurate, and they have preferred giving those which result immediately from their formula, to preserve in 
for computing Eclipses, Tables of Sines, \&ैc.

all its purity the table which was to serve for computing all the others: but they have given their tables of the equation of the centre for every degree.

Their theory for computing these tables of equations was incomplete and inaccurate; although they used epicycles, like the Greeks, to compute the inequalities of the plancts, this calculation was with them less geometric than those of Ptolemy. They had introduced an empiric correction, which was very badly conceived; and they supposed that from $90^{\circ}$ to $180^{\circ}$ the same equations returned in an. inverted order. The Greeks, in this respect, were further advanced than the Hindoos; their trigonometry was much more complete, although that of the Hindoos had a greater resemblance to ours; and the Hindoos appear to have had some theorems unknown to the Greeks. These tables of equations, although defective, are, nevertheless, very curious: in the explanation of them gixen by the Hindoos we observe that the differences of the equation are proportional to the sine of the anomaly; or, which is nearly the same, that the variation of the sine is proportional to the cosine.

It is evident also from this memoir, that the Hindoos found the latitude of a place by computing the length of the shadow of a gnompn, especially when the sun was in the equator; they might have found it also by the solstitial shadow, using the sun's greatest declination, which according to them was $24^{\circ}$.

To determine their longitudes they observed cclipses, and compared them with the computations made from their lunar tables adapted to their first meridian.

In page 315 is shown their method of calculating the sun's right ascension by means of their sines, without knowing the tangents.

In the same place is also shown how they computed the ascensional differences and the point of the equator which. rises with each sign. The table which they made luas been published by M. Le Gentil, who acknowledged he was unacquainted with the principle on which it was constructed: this principle is given in lise memois, and I have explained it at full length in a note. 
We shall not enter into any discussion respecting the antiquity of the Sontria Siddanta* : by only considering the form of their tables, their ideas of the precession of the equinoxes, their obliquity of $24^{\circ}$, and their theory of eclipses, we believe the authors of the Hindoo astronomical books more antient than the astronomers of Alexandria. On the other hand, when we find things known to them that were unknown to the Greeks, we should be inclined to consider them of a more recent date. The system of epicycles for the planets is common to them both, but less perfect than that of the Greeks; whence we may conjecture that this doctrine of the Indians passed from them to Greece, where it was extended and improved. It appears less natural to suppose that the Hindoos received them from the Greeks through the intermedium of the Arabs, cn account of the imperfect and disfigured theories which arc found among them. We can, howerer, affirm that this memoir, although nothing is to be obtained from it that can improve our present knowledge or the progress of astronomy, is nevertheless extremely curious, and worthy the attention of astronomers. What renders the reading of it more clifficult is, the great number of Indian technical words contained in the translation. They ought to have given a second version, in which there should have been no other than their own language: I had that idea, but to execute it completely some notions were necessary which I could not obtain, and some researches to which I had not time to attend.

In the same memoir we observe that the great period of the Indians, which is $4,320,000$ years, is only an astronomical period, at the beginning of which the mean longitudes, the aphelia, and the nodes of all the planets were nothing. At the end of this memoir we find another tending to prove that the Inciian zodiac has not been borrowed either from the Greeks or the Arabs. We find also two memoirs on Indian chronology by sir William Jones.

In the appendix, p. 68, is given a memoir by Reuben Bur-

- An ingenious Fnglishman made this book 3840 years old; but since that, in 1793 , he has reduced this number to 731 , of about the year 1268 of our ara. 
rows, where he wishes to prove that Newton's binomial theorem was known to the Indians. In the notes I have answered the proofs which he brings forward to support his opinion, as they appear to me to have no foundation.

The first volume, which is very interesting to orientalists, contains nothing for astronomers; but every reader will see there, with great pleasure, a memoir on the gods of Italy, Greece, and India, by sir William Jones, with notes by M. Laaglès.

11I. Problems on the Reduction of Angles. By T.S. Evans, F.L.S., of the Royal Military Academy, Woolwich*.

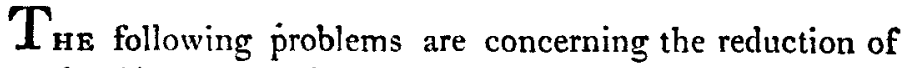
angles from one point or plane to another. They are not all of them new. One or two, with their solutions, will be found among the writings of each of the following celebrated mathematicians; Boscovich, Cagnoli, Carnot, Delambre, and probably some others: but few, if any of them, have ever been published by our English authors. It was therefore thought, if their solutions were giren in one uniform manner, in our own language, they might be of service; and this is what $I$ have here attempted, with a few additions of my own.

As they bear a very near relation to both plane and spheric trigonometry, but cannot, with propriety, be consiciered as actually belonging to either of them separateiy, I have taken the liberty of classing them under the title of Goniometry.

Their utility will be cvident to every person who has any concern in geodesic operations. It seldom happens in practice that all the three objects at the angular points of a triangle are situated precisely in the horizontal plane passing through the observer's eye; therefore when one or two of them are above or below that plane the angles are different, and will require to be reduced to what they would be if the

* Communicated by the Author. 